\title{
EXPANSION OF SATELLITE TOWNS' RESIDENTIAL AREA IN THE CONTEXT OF HIGHLIGHTING THE POLARIZING ROLE OF BIG METROPOLISES. CASE STUDY: MĂGURELE, ROMANIA
}

\author{
DOI: https://doi.org/10.18509/GBP210359p
}

UDC: 314.117(498)"2008/2020"

\author{
Bogdan Petre \\ Camelia Teodorescu \\ Alina Viorica Dumitrașc \\ Andrei Ducman \\ Cristian Cazacu \\ University of Bucharest, Faculty of Geography, Department of Human and Economic \\ Geography; Bucharest, Romania
}

\begin{abstract}
Satellite towns occurred as a natural response at the metropolises accelerated development and their residential area is continuously expanding. The town of Măgurele is a satellite town of the Municipality of Bucharest being situated in its south-western part. In the past years the town of Măgurele has undergone an extensive transformation process, fact which attracted a numerous population. Our study aims at emphasizing the peculiarity of Măgurele development in the context of highlighting the polarizing role of Bucharest Municipality. Moreover, the research has the objective of presenting the causes and the socio-economic consequences of the residential area expansion in Măgurele town. The research methodology had as a first step the application and analysis of questionnaire on a sample of 220 people who moved to Măgurele town between 2008 and 2020 in order to identify the causes which led to this. A second step was represented by the analysis of statistic data referring to the residential space and identification on site of the newly-built districts. Results show that the considerable expansion of Măgurele residential area was carried out by the movement of a relatively high number of young population (under 40 years old) coming from Bucharest Municipality. The causes which led to this situation are multiple ranging from Bucharest overcrowding to people's wish to live in a cleaner air environment. Furthermore, the status of scientific centre that Măgurele has received in the past years was also identified as a cause of residential area expansion. Our research is only in the beginning phase but we aim to observe in the future the phenomenon and its socio-economic implications.
\end{abstract}

Keywords: migration, sociology, geography, economy, urban

\section{INTRODUCTION}

The concept of bedroom cities (or dormitory communes) is often found in the vicinity of capital cities, but also large cities, taking place in the form of an annular strip around the polarizing urban center [2][10][11]. Most of the localities arranged within this sleeping ring, present an artificial development, extremely sudden and with a branched disposition of the territory, through very fast increases of the housing fund, in a way in which the organization is not the main element of development [1][7][12]. Through the possibilities of territorial extension to the outside, they can become urban centers proper, they can develop economic relations as diversified and beneficial for both centers, facilitating the 
flows of information, labor or investment between the two centers [3][9]. Bucharest is the most important city in the regional and national plan, with a population of approximately three million inhabitants today, continued indirectly in the area of Ilfov County, an area it controls economically, offers migration trends and promotes real estate activity in them, as the costs are lower, the bedroom centers being located along an important road axis within the municipality [4][8]. By relocating the population from the direction of Bucharest - bedroom centers, their population will increase considerably, important resources and sums will be invested within the territorial reality, increasing the real estate, tourist and investment interest. Magurele is one of the extremely interesting bedroom centers of the capital, by its location along the ring road, which surrounds the capital, sectioning the town into two distinct areas [5][6] Due to its proximity to Bucharest, Magurele is not only a sleeping center for part of the population relocated to the peripheral area, but is also a center of the Quaternary sector, through the National ResearchDevelopment Institute for Physics and Nuclear Engineering "Horia Hulubei" and the numerous patents of Romanian science, including the famous laser from Magurele.

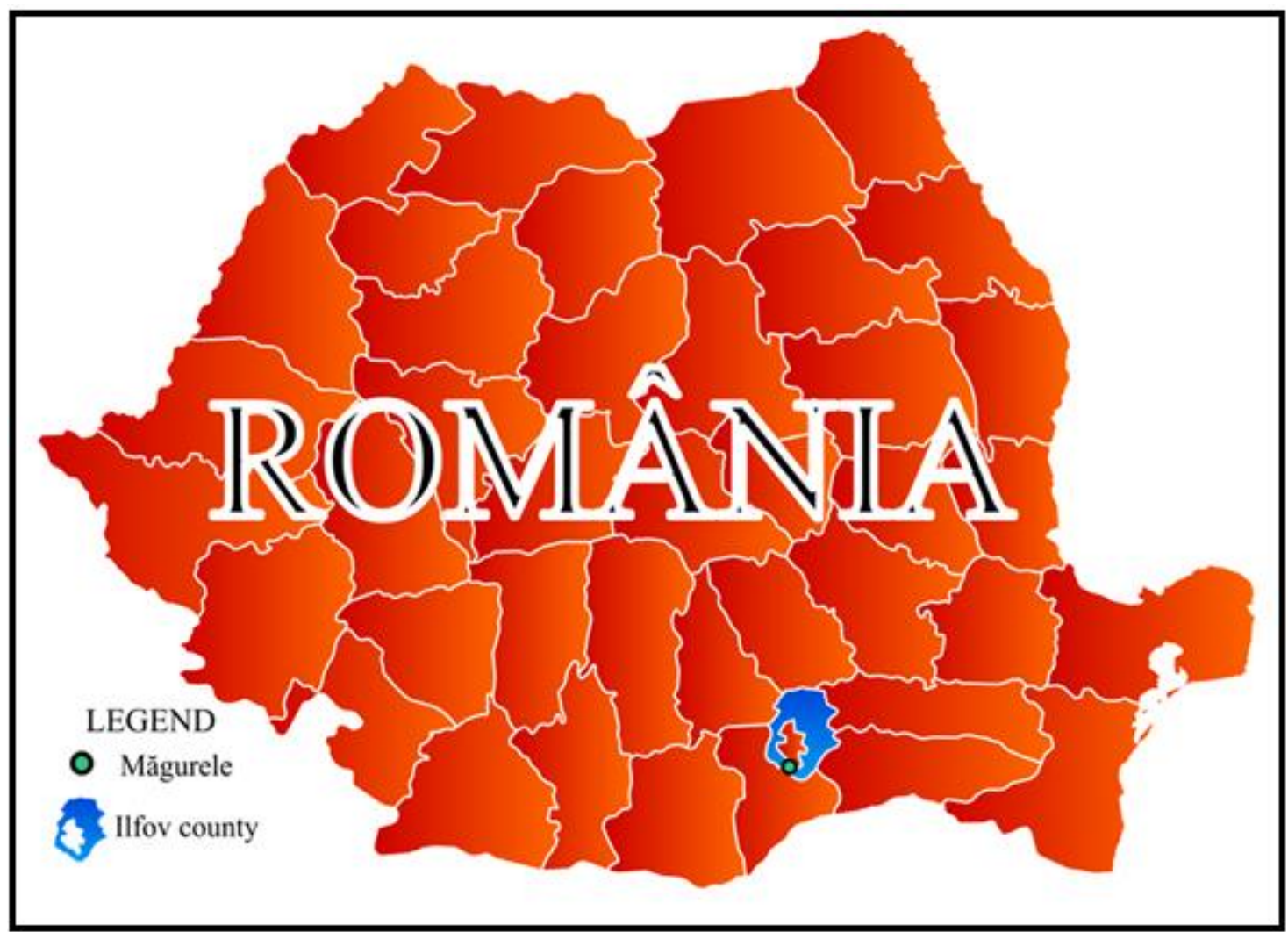

Figure 1. Magurele city location map (nationally and locally)

The research proposes an identification of the motivations, needs, behaviors and attitudes of the people who made the relocation to Magurele, in the period $2008-2020$, through a representative sample of 220 people, developed on a general character, regardless of socio-human category, financial level or age, the only niche of the questionnaires being guided to the need of the respondents to have moved to the locality recently. The study proposes to identify the main reasons for the campaign to permanently move to Ilfov, wanting to identify the dominant financial category of respondents, the most significant age category in the migration process, but also data of interest in the migration process. . The questionnaire campaign was conducted exclusively online, through groups on social 
networks related to the city of Ilfov, selecting only the questionnaires of residents who previously lived in Bucharest. The data were obtained in a period of a month and a half, especially in the spring - summer of 2020, supplemented with statistical data provided by the National Institute of Statistics, on the increase of housing in the analyzed period, but also statistical data with regarding the population growth in the city of Ilfov. The centralization and selection of data was done with the help of the Microsoft Office bundle, especially Microsoft Excel for creating graphics.

\section{RESULTS}

The questionnaire campaign reveals that the chosen sample permanently fueled the migration process on the axis Bucharest - Magurele, discussing a relocation of at least eight respondents annually, discussing an upward growth trend, through a historical maximum of thirty-four new residents, for 2017. The premises are positive, regarding the increase of the number of residents from Magurele locality, discussing about an extremely easy access way to enter the capital, but also through a very short distance and extremely relevant economic possibilities. (Figure 2)

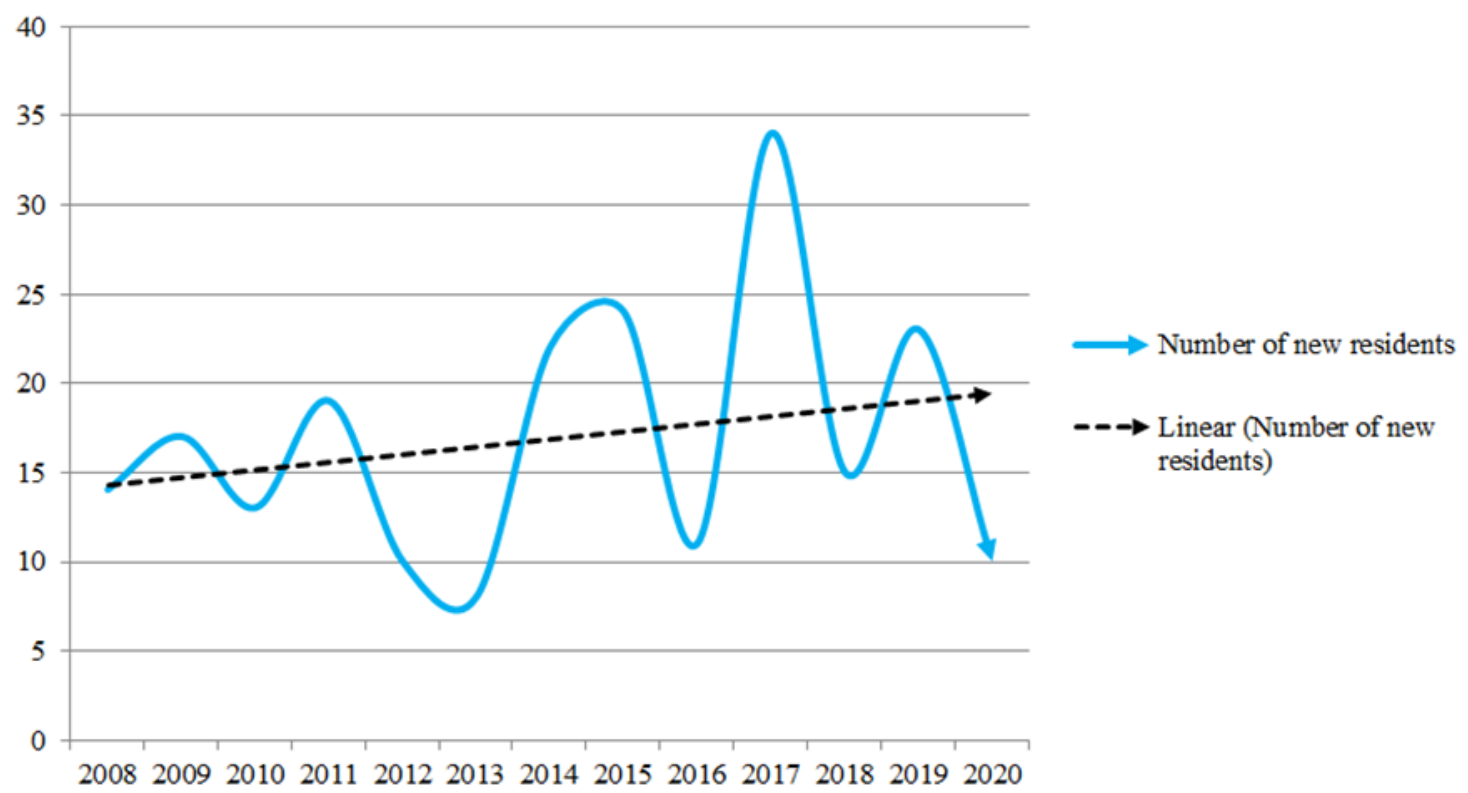

Figure 2. The year in which the relocation of the residents on the axis of Bucharest - Magurele took place

The main category of respondents is represented by residents who have their own housing, either purchased from personal sources or purchased through the government program "First House", launched by the Romanian Government, followed by multifamily housing (blocks), which are inhabited rent, $22 \%$ of respondents prefer this type of housing. $19 \%$ of respondents prefer to live in single-family homes (houses), while only $14 \%$ of residents have purchased a home in a multi-family block, either from personal sources or through the government program mentioned above. The lowest category of respondents is that of the sample living in personal or relatives' homes, obtained by inheritance or donation, or by living with other family members. (Figure 3 ).

Only $19 \%$ of $46 \%$ of respondents live in the form of a marriage, discussing mainly new families who have opted for the government's home purchase program, but also families who have opted for their own home purchase, followed by housing in the form of a couple, most respondents wanting to move to marriage in the near future. $21 \%$ of respondents 
live individually and privately, in the form of owned or rented housing, while only $9 \%$ of residents live permanently with other family members. (Figure 4)

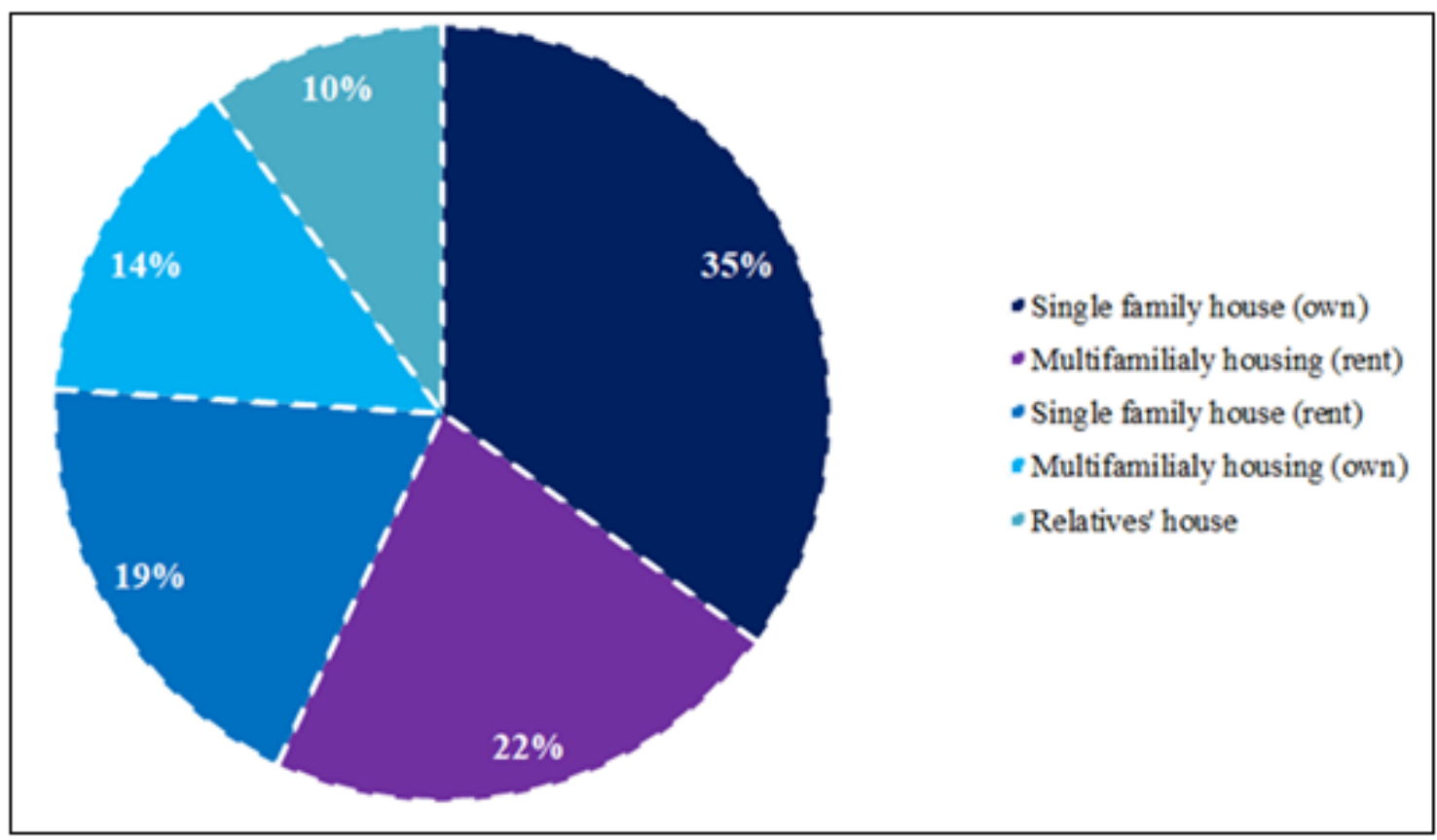

Figure 3. Types of houses of the respondents from Magurele locality

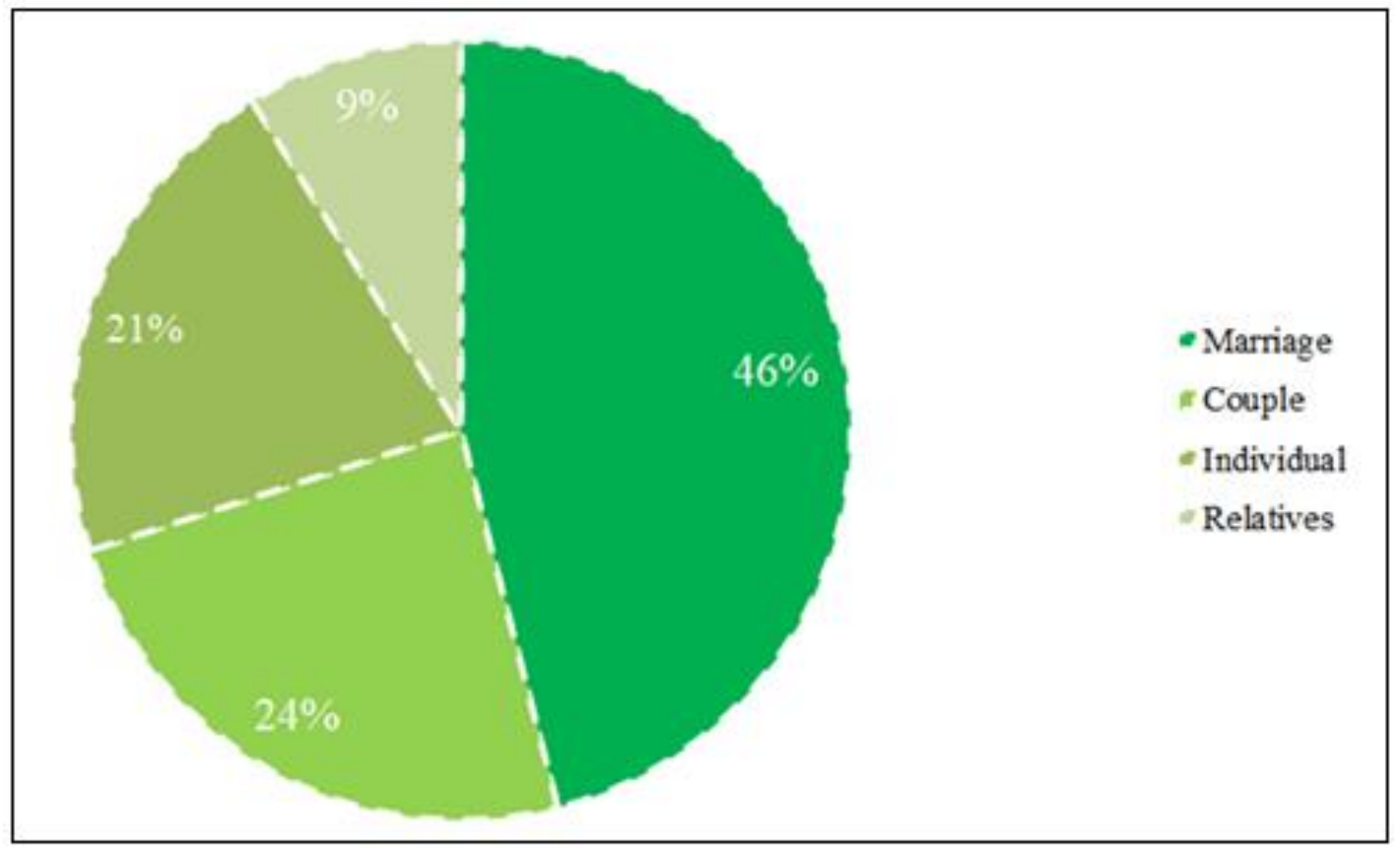

Figure 4. The way of living of the respondents from Magurele locality

Through the possibility of purchasing housing for a period of thirty years, newly married couples jointly choose to purchase housing through government programs, totaling $41 \%$ of all respondents, followed by an important category of residents who have chosen to create their own purchase loan, in one of the important banks of Romania. respondents were able to purchase a home from their own savings, most of them being people who 
own at least one medium-level business. Also, the lowest category of the indicator is that of the respondents who obtained a house for free, by inheritance or donation, living in them individually or together with their own family. (Figure 5)

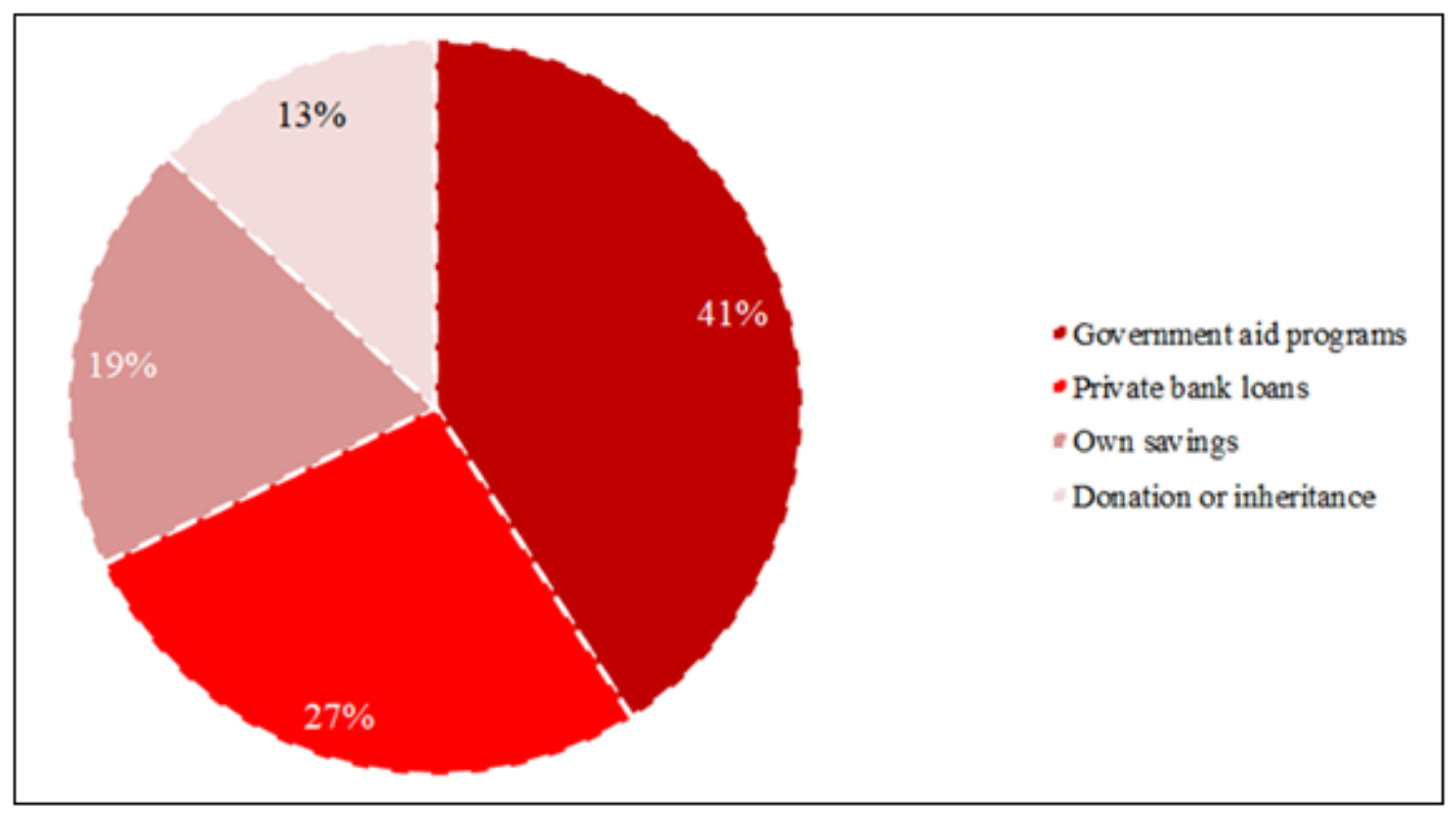

Figure 5. How the respondents acquire the houses in Magurele

The dominant economic sector of the respondents of the questionnaire campaign is the tertiary sector, discussing an important presence of the Magurele population in the services sector, followed by the Quaternary sector, in terms of the presence of numerous scientific centers in Ilfov, with a share of $30 \%$. The industrial sectors and destined to the lucrative physical activities represent only a quarter of the total of the respondents, these working mainly in the Bucharest industrial platforms located in Sectors 5 or 6. (Figure 6) The main motivation of the respondents is the purchase of a house, in terms of financial accessibility and accessibility to the Bucharest area, followed by family reasons, such as the appearance of a child or the establishment of a family, by a percentage of $15 \% .25 \%$ of the respondents wanted to migrate to Ilfov locality based on employment in the vicinity of the locality or within it, the category being representative for people engaged in the quaternary sector. $24 \%$ of respondents considered that urban stress, generated by Bucharest, is above normal values, wanting to migrate to obtain a general peace, away from congested road traffic, people or other personal problems. Only $4 \%$ of respondents migrated to the city of Magurele in order to obtain a house, free of charge (donation or inheritance). (Figure 7) 


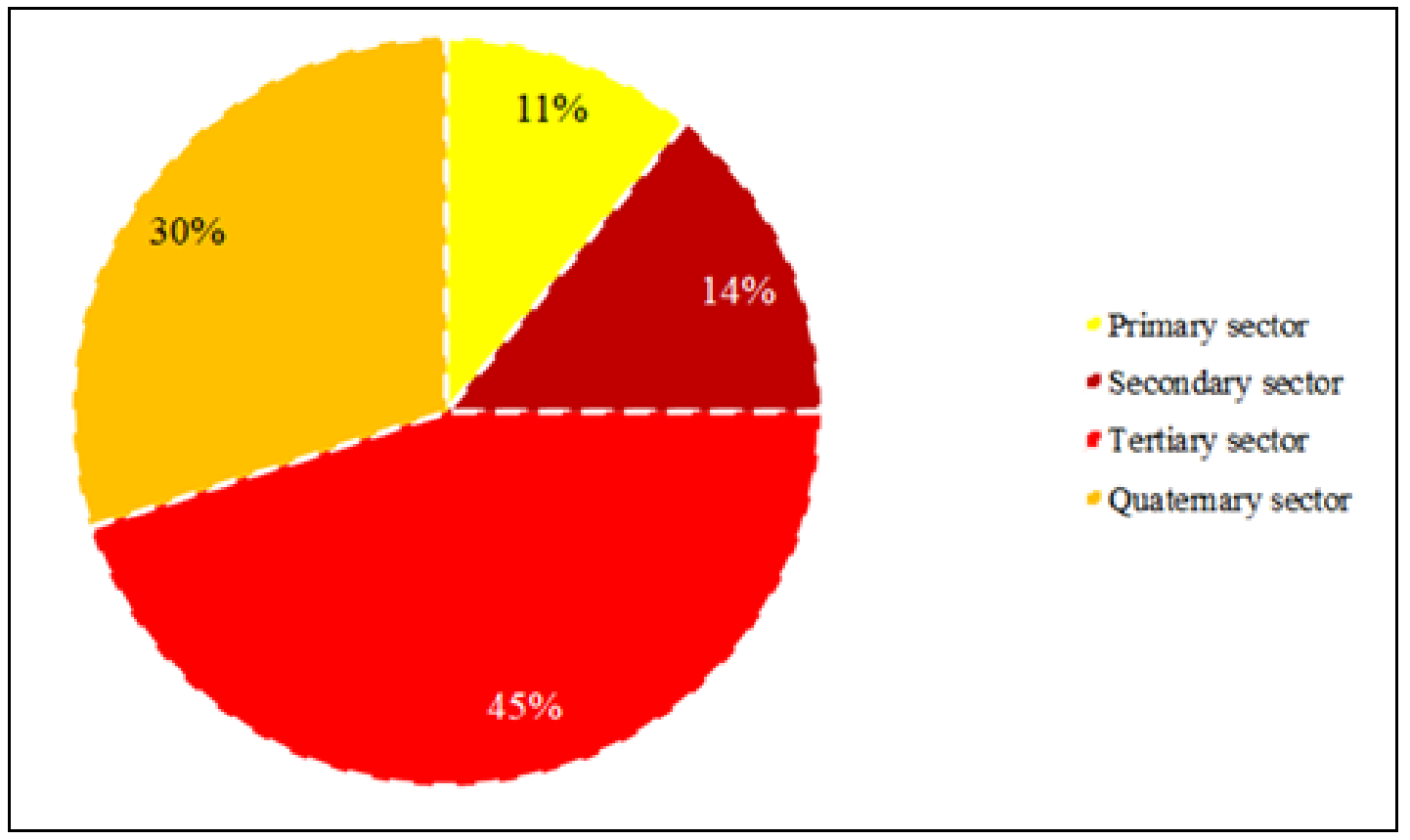

Figure 6. The economic sector in which the sample of the questionnaire campaign is engaged

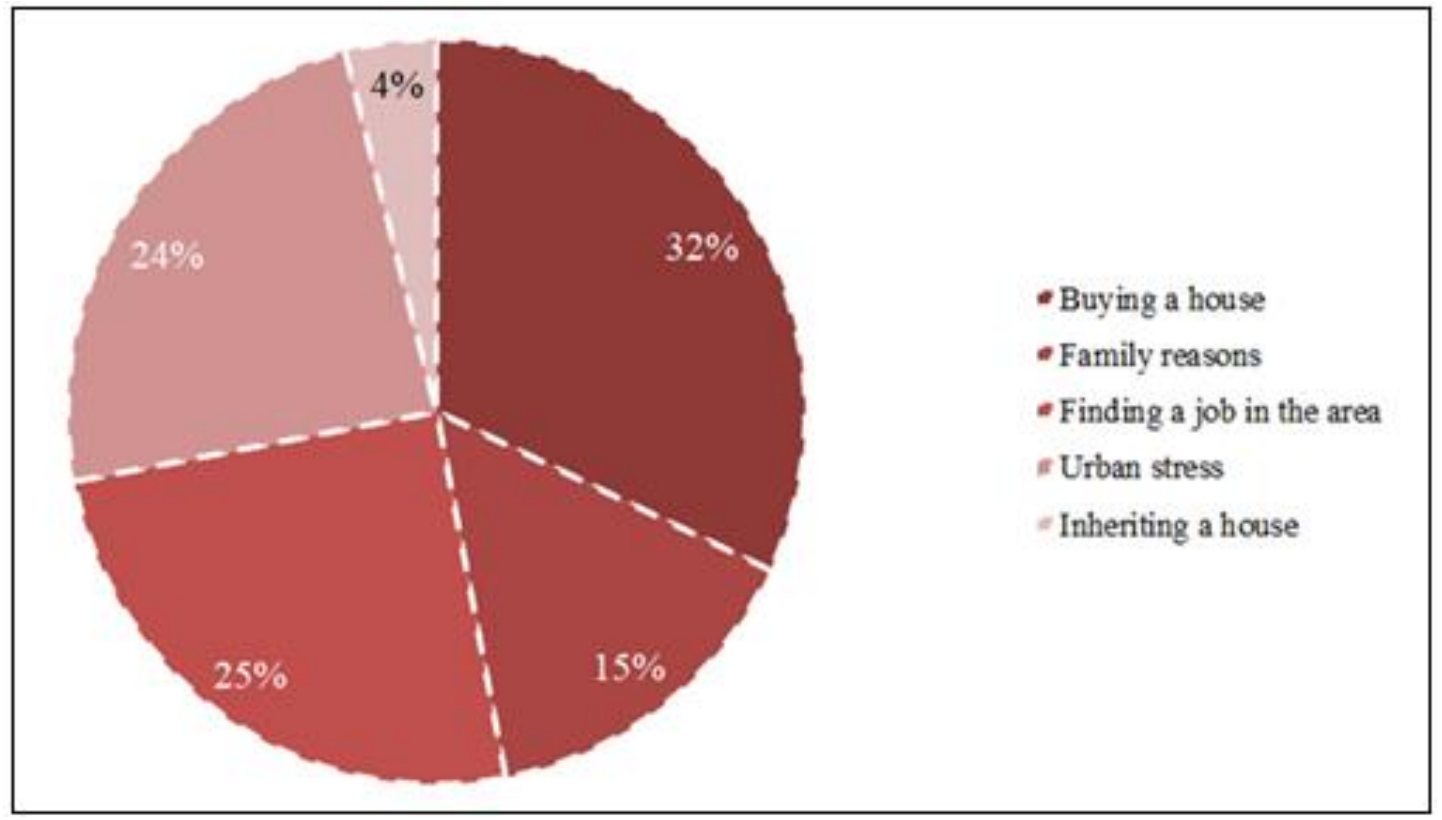

Figure 7. Motivation of the respondents to migrate on the axis Bucharest - Magurele

The number of new homes in the city of Magurele is experiencing a permanent and staged increase, with the appearance of at least 75 new homes, especially single-family homes that have been introduced in the government's housing acquisition program for newlyweds. The growth is guaranteed by a territorial extension and a location that allows the development along the National Road Bucharest Beltway, but also in the southern part of Magurele, by the presence of an important agricultural fund, which could be transformed into a much more beneficial real estate fund, in terms of the fact that agriculture is still an important economic sector for the city of Ilfov. (Figure 8)

The evolution of the population is ascending, increasing during the analyzed period with approximately 3300 new inhabitants, most of them coming from Bucharest, the increase 
being correlated with the increase of the housing fund capacity and by increasing the accessibility on the axis Bucharest - Magurele city. The positive trend offers positive premises regarding the future of the Ilfov city, the growth guaranteeing the necessary economic, social and entrepreneurial development. (Figure 9).

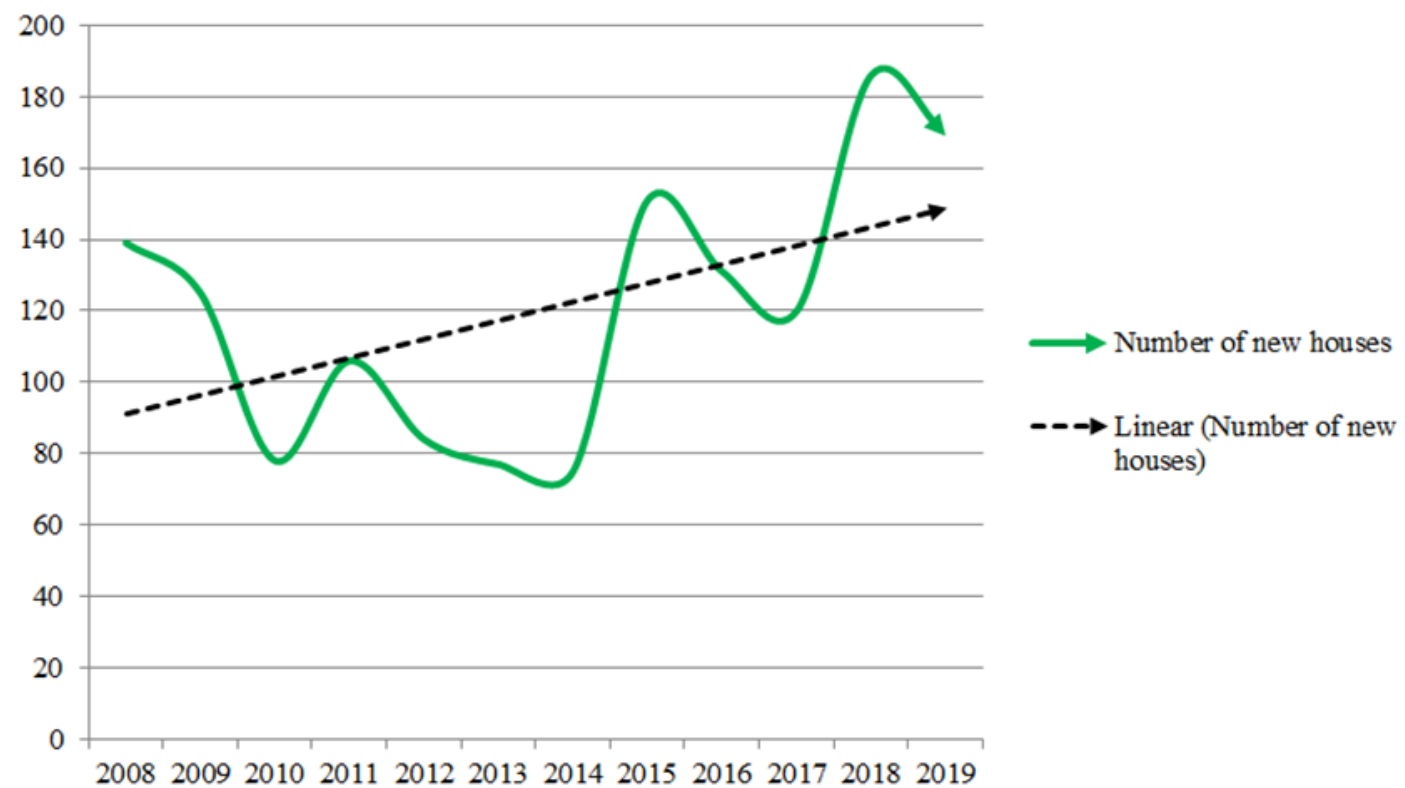

Figure 8. Evolution of number of new houses in Magurele (2008 - 2019)

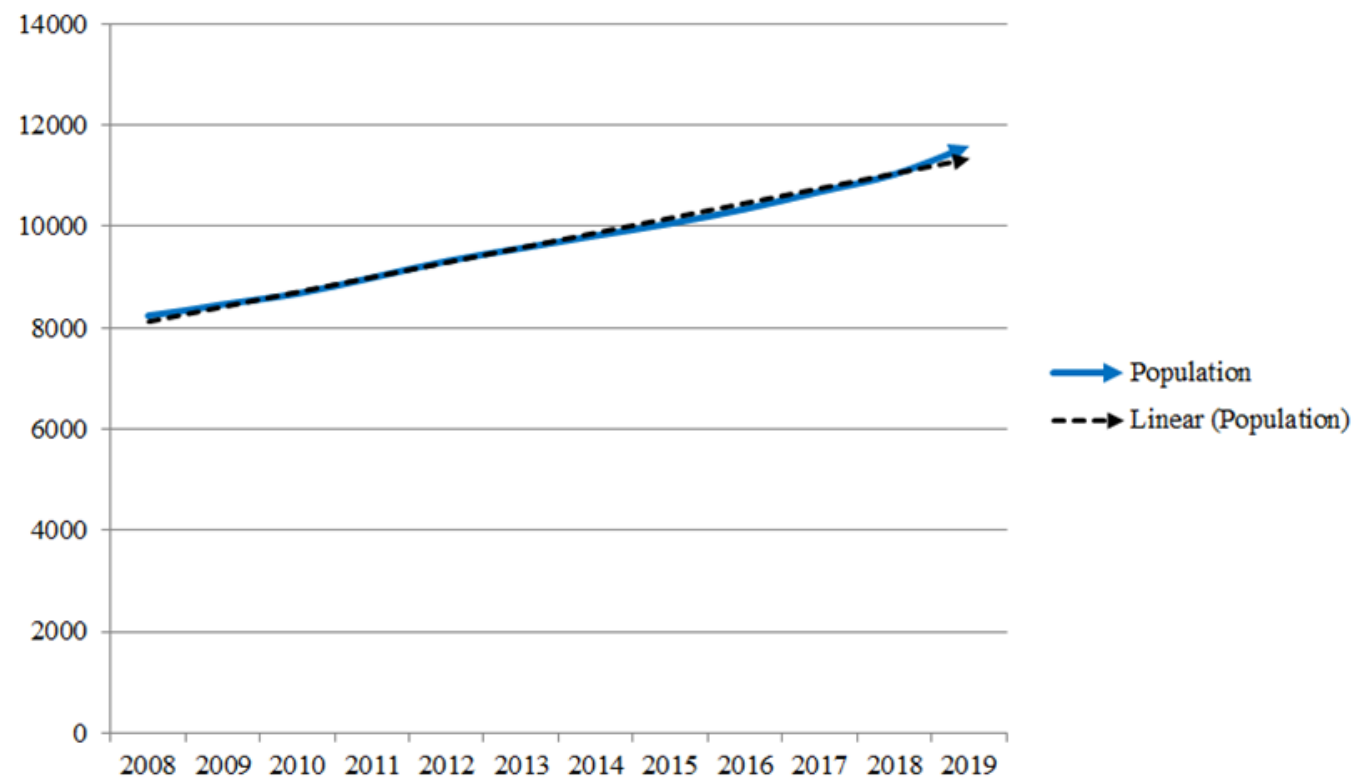

Figure 9. Evolution of the number of population of Magurele (2008 - 2019)

\section{CONCLUSIONS}

The city of Magurele is one of the most important dormitories in Bucharest, through the increased possibility of territorial expansion, the desire of the population to get involved in real estate, increased interest from potential immigrants, but also through positive economic prospects and aimed at success . The economic and social relationship between Magurele and Bucharest offers benefits for both localities, discussing permanent 
exchanges of information, labor, resources and products that can be sold on both economic markets, but also extremely beneficial investment exchanges. The research meets the initial objectives, establishing that most respondents produced migration based on family reasons, based on financial and transport accessibility with Bucharest, but also based on the fact that Magurele has important individual economic prospects, through the important development of the tertiary sector and quaternary inside the locality. Also, the study confirms that the population of Magurele is constantly growing, and the housing stock is in a process of territorial expansion, adapted to the territorial reality of Ilfov, offering important perspectives on population growth and investment in the locality. . The questionnaire campaign was a success, as the purpose of the study was to raise awareness among residents about the need for objective analysis of personal living possibilities, weighing all variables that could lead to a migration to the outskirts of Bucharest, in view of the fact that urban stress and the desire to develop the family in a quiet and unpolluted space are necessary in thinking about the future.

\section{REFERENCES}

[1] Bousbaine, A.D. \& Bryant, C., 2020. Chapter 8 - Urbanization, urban agriculture and food security, Urban Ecology, Emerging Patterns and Social-Ecological Systems, pp. 131-144.

[2] Boussougou Boussougou, G. et. al, 2021. Identifying agricultural areas with potential for city connections: A regional-scale methodology for urban planning. Land Use Policy, Vol. 103, available online at: https://doi.org/10.1016/j.landusepol.2021.105321

[3] Caruso, G. et. al, 2007. Spatial configurations in a periurban city. A cellular automata-based microeconomic model. Regional Science and Urban Economics, Vol. 37, Issue 5, pp. 542-567.

[4] Flores, A.D. et. al, 2020. A basin-level analysis of flood risk in urban and periurban areas: A case study in the metropolitan region of Buenos Aires, Argentina. Heliyon, Vol. 6, Issue 8, available online at: https://doi.org/10.1016/j.heliyon.2020.e04517.

[5] Pintilii R.D. et. al, 2017. Socio-Economic Geography Creative economies in Romania-spatial projections and trends, Bulletin of Geography, Socio-economic Series, Vol. 37, pp 95-108.

[6] Rădoi I.V. et. al, 2020. The impact of the development of the local economy on the natural environment of the Danube Delta, Romania, Public recreation and landscape protection, pp. 489.

[7] Russo, P. et. al, 2014. Marginal periurban agricultural areas: A support method for landscape planning, Land Use Policy, Vol. 41, pp. 97-109.

[8] Teodoresc, C., \& Szemkovics, L.S., 2017. The ethno-creativity in the pilot centers in Romania and their role in the development of cultural tourism and the educational process, Geographical studies and environment protection research vol. 16, nr. 1, pp. 88-97, 2017

[9] Teodorescu C. et. al, 2019. Disfunctionalities in the Organization and Development of SPA Tourism Developed on Salt Resources in Maramureș, Romania, Public Recreation and Landscape Protection, Vol. 1, pp 101-105.

[10] Teodorescu C. et. al, 2016, Religious and cultural tourism and the socio-economic and educational implications. Quaestus Multidisciplinary Research Journal, Vol. 8, pp 227- 285.

[11] Teodorescu C. 2009. Turism cultural, Editura Transversal, Targoviste, Romania.

[12] Wandl, A, \& Magoni, M., 2016. Sustainable Planning of Peri-Urban Areas: Introduction to the Special Issue. Planning Practice \& Research, Vol. 32, Issue 1. 